\title{
ISOMETRIC HANDGRIP: A TOOL TO EVALUATE SYMPATHETIC DOMINANCE IN OFF SPRINGS OF HYPERTENSIVE PARENTS AND ROLE OF DIET IN THEM
}

\author{
Vishrutha K. V1, Arati P. Rao'2, Harini Narayanam³, Vandana 4 \\ ${ }_{1}^{1}$ Associate Professor, Department of Physiology, Srinivas Institute of Medical Sciences and Research Centre, Mukka, Mangalore. \\ ${ }^{2}$ Associate Professor, Department of Physiology, Srinivas Institute of Medical Sciences and Research Centre, Mukka, Mangalore. \\ ${ }^{3}$ Assistant Professor, Department of Physiology, Anna Medical College, Mauritius. \\ ${ }^{4}$ Assistant Professor, Statistics Unit, Fisheries College.
}

\section{ABSTRACT}

\section{BACKGROUND}

Genetic factors likely play some role in causing a high blood pressure. About $30 \%$ of patients with primary hypertension have genetic predisposition. It is a well-documented fact that sympathetic dominance increases heart rate and blood pressure and the same has been observed in young normotensive off springs of hypertensive parents.

\section{AIM}

Aim of the present study was to evaluate pulse and blood pressure responses to isometric hand grip in children of hypertensives and non-hypertensives.

\section{METHODS}

The present study was conducted in 120 subjects, 59 of whom had a positive family history and 61 had no family history of hypertension. Isometric hand grip as a sympathetic test was carried out in both the groups following measurement of resting pulse and blood pressure. Five minutes following isometric hand grip pulse and blood pressure recordings were taken. Children of hypertensives were further divided into vegetarian and non-vegetarian group and the same parameters were compared in them before, during and after conducting isometric handgrip.

\section{RESULTS}

Results were tabulated and analysed using Independent ' $\mathrm{t}$ ' test. $\mathrm{P}$ value $<0.05$ was considered as significant. A statistically significant increase in pulse and blood pressure values were obtained in children of hypertensives at rest during and five minutes after performing isometric handgrip. Findings are suggestive of an increased sympathetic dominance in children of hypertensives. Higher pulse and blood pressure values in resting state, during and after the procedure were obtained in non-vegetarian group of hypertensive children. However, these values were not statistically significant.

\section{CONCLUSION}

The present study suggests that healthy children of hypertensive parents do have a sympathetic dominance when compared to healthy children of non-hypertensive parents.

\section{KEYWORDS}

Isometric Hand Grip, Blood Pressure, Diet.

HOW TO CITE THIS ARTICLE: Vishrutha KV, Rao AP, Narayanam H, et al. Isometric handgrip: a tool to evaluate sympathetic dominance in off springs of hypertensive parents and role of diet in them. J. Evolution Med. Dent. Sci. 2016;5(20):1049-1052,

DOI: $10.14260 /$ jemds/2016/244

\section{INTRODUCTION}

Hypertension is one of the most important causes of premature deaths occurring worldwide and thus is claimed to be a silent killer by the World Health Organization. In India, hypertension is the third most important risk factor burdening both cardiovascular health and health care systems in the country; $57 \%$ of all stroke deaths and $24 \%$ of coronary heart diseases are attributed to hypertension. As per the studies conducted by Raghupati Anchala, 33\% of urban and $25 \%$ of rural Indians are hypertensive. ${ }^{1}$ Fortunately, early diagnosis can prevent about 3 lakh deaths in India. ${ }^{2}$

Financial or Other, Competing Interest: None.

Submission 12-02-2016, Peer Review 23-02-2016,

Acceptance 26-02-2016, Published 10-03-2016.

Corresponding Author:

Vishrutha K. $V$

Associate Professor,

Srinivas Institute of Medical Sciences and Research Centre,

Mukka, Mangalore.

E-mail: kvvishrutha@gmail.com

DOI: 10.14260/jemds/2016/244
An increasing prevalence of the condition is blamed on lifestyle factors such as stress, physical inactivity, a salt rich diet created by processed, fatty foods and alcohol and tobacco use. ${ }^{3}$ Genetic factors likely play some role in causing a high blood pressure. About $30 \%$ of patients with primary hypertension have genetic predisposition..$^{4}$ several genes are implicated to onset of hypertension. Few of them are genes that encode for components of renin-angiotensin-aldosterone synthesis, angiotensinogen, angiotensin-converting enzyme, angiotensin receptor, atrial natriuretic peptide, etc.

Moreover, there is a two-fold increase in occurrence of cardiovascular disease which include coronary heart disease, congestive heart failure, stroke and renal failure in patients suffering with hypertension. ${ }^{5}$ Children with one hypertensive parent have a $25 \%$ probability of developing high blood pressure and in children with both the parents being hypertensive the probability of developing hypertension increases to $50 \% .^{6}$ Occurrence of high blood pressure before a person reaches 55 years of age occurs 3.8 times more frequently among persons with a family history of hypertension. ${ }^{5}$ 
It is likely that people with a family history of high blood pressure share common environments and other potential factors, which might increase their risk of developing hypertension. Heredity combined with unhealthy lifestyle choices, such as smoking cigarettes and eating unhealthy diet makes a person most susceptible to hypertension.

It is a well-documented fact that sympathetic dominance increases heart rate and blood pressure and the same has been observed in young normotensive off springs of hypertensive parents.7,8 They also manifest an elevated level of blood pressure during and after 5 minutes of exposure to physical stress. ${ }^{9}$ Certain other researchers found no sympathetic dominance in children born to hypertensive parents. ${ }^{10}$ Hence, evaluating cardiac autonomic function may prove to be useful as a predictive tool in diagnosis of impending high blood pressure.

Isometric handgrip dynamometer is a simple tool, which can be used with ease. Hence, using a dynamometer to demonstrate autonomic modulation is a simple and inexpensive method. While performing exercise using a dynamometer, there is an increase in heart rate and blood pressure due to stimulation of efferent sympathetic pathway. ${ }^{11}$ Also an increased tension produced in muscles due to isometric contraction increases the arterial pressure with a small increase in heart rate and cardiac output. In addition, there is also a rise in peripheral vascular resistance, which accounts for increase in diastolic blood pressure. ${ }^{12}$

An impressive study dating back to the early 1920s show that vegetarians have lower blood pressure than nonvegetarians. The reasons are not hard to find.Vegetarian meals are typically low in saturated fat and usually contain little or no cholesterol.

The present study was undertaken to evaluate if a sympathetic dominance exists in the off springs born to hypertensive parents and to compare them with their respective diets. A special focus on the diet as early modification of the same may improve quality of life.

\section{MATERIALS AND METHOD}

The present study was undertaken in Srinivas Institute of Medical Sciences and Research Centre after an ethical clearance. The study group comprised of 120 volunteers in the age group of 19 to 22 years. Height and weight of the subjects were matched. Out of them 59 subjects had a family history of hypertension, i.e. either parents or both; 61 subjects had no family history of hypertension; out of 59 subjects with family history of hypertension 29 were vegetarian and 30 were nonvegetarian.

Subjects with history of any chronic disease, smokers and subjects on any medication were excluded from the study. Group $1(\mathrm{n}=59)$ included subjects with family history of hypertension. Group $2(\mathrm{n}=61)$ has subjects with no family history of hypertension. Group $3(n=29)$ comprises subjects who are vegetarian with a family history of hypertension, group $4(n=30)$ consists of non-vegetarian subjects with a family history of hypertension.

Blood pressure was recorded using auscultatory method with a mercury type sphygmomanometer of Diamond make. Basal blood pressure in sitting posture was recorded on three separate occasions to confirm that volunteers were normotensive. Only those subjects whose basal blood pressure in sitting posture was normal were included in the study.
After the subjects rested for a period of five minutes, pulse and blood pressure was recorded in them using auscultatory method and documented.

Isometric handgrip dynamometer of the spring type was used in the study. Subjects were briefed on how to use the instrument before conducting the procedure. The paddles of the dynamometer were compressed with maximum effort with the dominant hand. The dynamometer has two needles, one remains at zero while the other needle portrays maximal voluntary contraction. The subjects were made to perform the same manoeuvre thrice with a brief interval of 30 seconds to prevent fatigue. The readings were documented respectively. Mean of the three readings was calculated and documented ( $\mathrm{T}$ max); $30 \%$ of the T-max was calculated and subjects were asked to maintain the same for a period of 2 minutes. Pulse and blood pressure were recorded simultaneously in the nondominant arm during the procedure and after a rest of five minutes. Blood pressure in resting state during the procedure and 5 minutes after the procedure was compared between group 3 and 4 .

\section{RESULTS}

Results were tabulated and analysed using Independent ' $\mathrm{t}$ ' test. $P$ value $<0.05$ was considered as significant.

\begin{tabular}{|c|c|c|c|}
\hline & \multicolumn{3}{|c|}{ Before Isometric Handgrip } \\
\hline & $\begin{array}{c}\text { Pulse } \\
\text { (beats/min) } \\
\text { Mean } \pm \text { SD }\end{array}$ & $\begin{array}{c}\text { SBP (mmHg) } \\
\text { Mean } \pm \text { SD }\end{array}$ & $\begin{array}{c}\text { DBP (mmHg) } \\
\text { Mean } \pm \text { SD }\end{array}$ \\
\hline $\begin{array}{c}\text { Group 1 } \\
(\mathrm{n}=59)\end{array}$ & $80.14 \pm 5.65^{*}$ & $115.3 \pm 12.69^{*}$ & $75.29 \pm 7.70^{*}$ \\
\hline $\begin{array}{c}\text { Group 2 } \\
(\mathrm{n}=61)\end{array}$ & $76.84 \pm 6.26$ & $110.30 \pm 8.93$ & $72.13 \pm 7.45$ \\
\hline \multicolumn{3}{|c|}{$\begin{array}{c}\text { Table 1: Comparison of Pulse, Systolic Blood Pressure } \\
\text { (SBP), Diastolic Blood Pressure (DBP) between Group 1 } \\
\text { and 2 before Isometric Handgrip }\end{array}$} \\
\hline
\end{tabular}

\begin{tabular}{|c|c|c|c|}
\hline & \multicolumn{3}{|c|}{ During Isometric Handgrip } \\
\hline & $\begin{array}{c}\text { Pulse } \\
\text { (beats/min) } \\
\text { Mean } \pm \text { SD }\end{array}$ & $\begin{array}{c}\text { SBP (mmHg) } \\
\text { Mean } \pm \text { SD }\end{array}$ & $\begin{array}{c}\text { DBP } \\
\text { (mmHg) } \\
\text { Mean } \pm \text { SD }\end{array}$ \\
\hline $\begin{array}{c}\text { Group 1 } \\
(\mathrm{n}=59)\end{array}$ & $90.41 \pm 11.3^{*}$ & $132.07 \pm 12.32^{*}$ & $88.92 \pm 8.95^{*}$ \\
\hline $\begin{array}{c}\text { Group 2 } \\
(\mathrm{n}=61)\end{array}$ & $84.93 \pm 11.63$ & $125.67 \pm 12.88$ & $85.61 \pm 7.09$ \\
\hline \multicolumn{3}{|c|}{$\begin{array}{c}\text { Table 2: Comparison of Pulse, Systolic Blood Pressure } \\
\text { (SBP), Diastolic Blood Pressure (DBP) between Group 1 } \\
\text { and 2 during Isometric Handgrip }\end{array}$} \\
\hline \multicolumn{4}{|c}{}
\end{tabular}

\begin{tabular}{|c|c|c|c|}
\hline & \multicolumn{3}{|c|}{ After Isometric Handgrip } \\
\hline & $\begin{array}{c}\text { Pulse } \\
\text { (beats/min) } \\
\text { Mean } \pm \text { SD }\end{array}$ & $\begin{array}{c}\text { SBP (mmHg) } \\
\text { Mean } \pm \text { SD }\end{array}$ & $\begin{array}{c}\text { DBP } \\
\text { (mmHg) } \\
\text { Mean } \pm \text { SD }\end{array}$ \\
\hline $\begin{array}{c}\text { Group 1 } \\
(\mathrm{n}=59)\end{array}$ & $81.56 \pm 5.38^{*}$ & $119.46 \pm 12.31^{*}$ & $78.47 \pm 6.50^{*}$ \\
\hline $\begin{array}{c}\text { Group 2 } \\
(\mathrm{n}=61)\end{array}$ & $76.84 \pm 6.27$ & $119.0 \pm 7.98$ & $72.30 \pm 8.11$ \\
\hline \multicolumn{3}{|c|}{$\begin{array}{c}\text { Table 3: Comparison of Pulse, Systolic Blood Pressure } \\
\text { (SBP), Diastolic Blood Pressure (DBP) between Group 1 } \\
\text { and 2 after Isometric Handgrip }\end{array}$} \\
\hline
\end{tabular}


Table 1, 2, 3 shows that there was a significant increase in pulse, systolic blood pressure and diastolic blood pressure before, during and after performing isometric handgrip between group 1 and 2 . The results were statistically significant.

\begin{tabular}{|c|c|c|c|c|}
\hline & & $\begin{array}{c}\text { Pulse } \\
\text { (beats } / \text { min) } \\
\text { Mean } \pm \text { SD }\end{array}$ & $\begin{array}{l}\text { SBP }(\mathrm{mmHg}) \\
\text { Mean } \pm \text { SD }\end{array}$ & $\begin{array}{c}\text { DBP } \\
\text { (mmHg) } \\
\text { Mean } \pm S D\end{array}$ \\
\hline \multirow{3}{*}{$\begin{array}{c}\text { Group } \\
3 \\
(n=29)\end{array}$} & Before & $79.93 \pm 5.8$ & $115.13 \pm 12.5$ & $75.13 \pm 7.6$ \\
\hline & During & $90.62 \pm 11.46$ & $131.73 \pm 12.42$ & $88.67 \pm 9.11$ \\
\hline & $\begin{array}{l}\text { After } \\
5 \mathrm{~min}\end{array}$ & $80.07 \pm 5.813$ & $119.0 \pm 12.1$ & $76.0 \pm 6.209$ \\
\hline \multirow{3}{*}{$\begin{array}{c}\text { Group } \\
4 \\
(n=30)\end{array}$} & Before & $81.34 \pm 5.57$ & $117.66 \pm 13.02$ & $76.22 \pm 7.87$ \\
\hline & During & $91.62 \pm 11.40$ & $132.41 \pm 12.43$ & $89.17 \pm 8.92$ \\
\hline & $\begin{array}{l}\text { After } \\
5 \text { min }\end{array}$ & $82.70 \pm 4.9$ & $120.98 \pm 12.7$ & $77.93 \pm 6.8$ \\
\hline
\end{tabular}

Table 4: Comparison of Pulse, SBP, DBP among vegetarians and non-vegetarians with family history of hypertension before, during and after Isometric Handgrip

Table 4 shows that although higher mean values of pulse, systolic and diastolic blood pressure was obtained in Group 4, the results were not statistically significant.

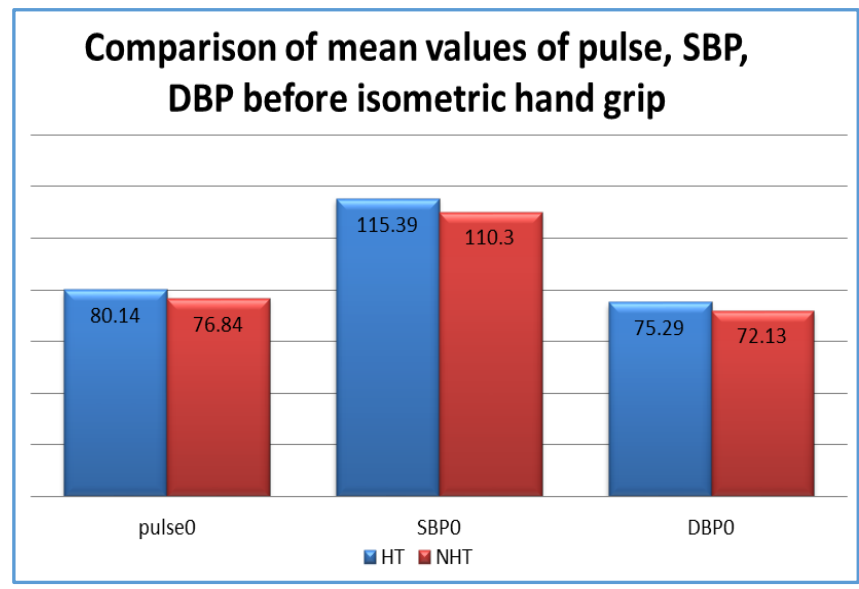

Fig. 1

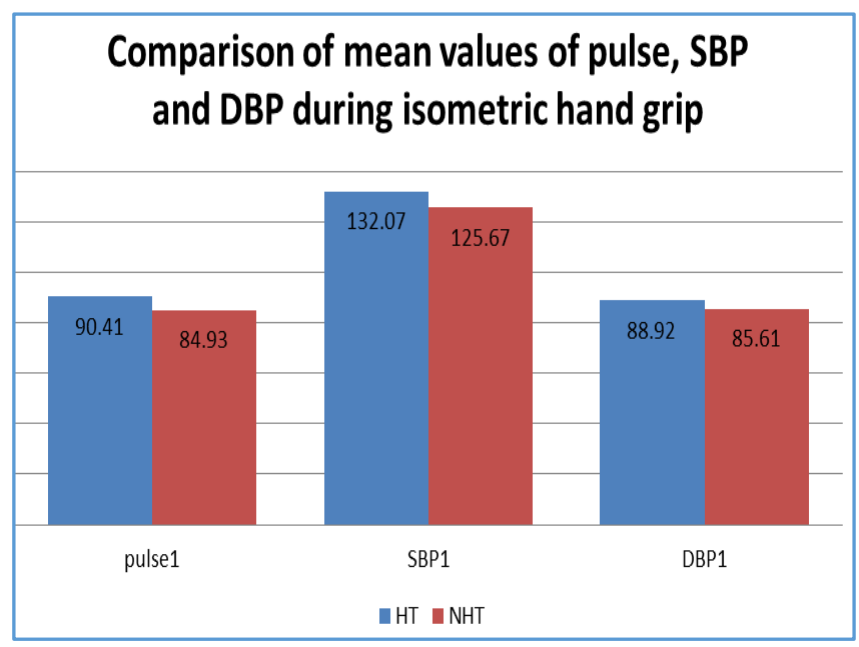

Fig. 2

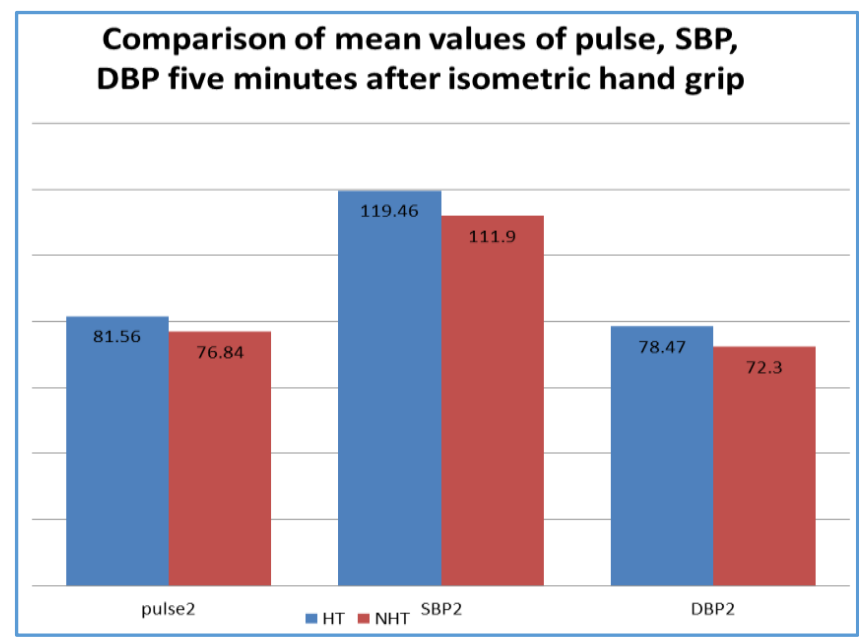

Fig. 3

\section{DISCUSSION}

The present study shows resting pulse, blood pressure and mean arterial pressure were significantly higher in off springs of hypertensive parents when compared to children of normotensive parents. While performing isometric handgrip manoeuvre, there was a significant increase in systolic blood pressure, diastolic blood pressure and mean arterial pressure in the study group. Five minutes after performing isometric handgrip manoeuvre, parameters returned to normal in the control group, whereas it did not in the study group. Isometric exercise when performed causes an increase in intramuscular pressure, which in turn compresses blood vessels within muscles. Compression of the vessels results in decreased muscle blood flow, which in turn causes an accumulation of metabolites within the muscle that stimulate muscle chemoreceptors resulting in an increase in sympathetic nerve activity. ${ }^{13}$ This in turn causes an increase in blood pressure during isometric exercise.

Although systolic blood pressure increased both in the study group and control group, the increase seen in study group was statistically significant. After 5 minutes' rest postprocedure blood pressure returned to normal in the control group, whereas it took a longer time to return to normalcy in the study group. Similar findings were reported by Schneider GM et al. and Lopes et al.7,14 The results obtained in this study are suggestive of a sympathovagal imbalance in off springs of hypertensive parents. This could be explained by findings obtained by Sherwood et al. They suggested that in the early stages, there is increase in cardiac output following which peripheral resistance increases in children of hypertensives owing to rise in blood pressures. ${ }^{15}$ Norepinephrine when infused in children of hypertensives, a greater pressor response was seen due to reduced threshold levels to norepinephrine in them. ${ }^{16}$

The study group was further split into two, a group with vegetarian diet and another with non-vegetarian diet. Isometric exercises were performed by them and the responses were calculated and documented. Although a rise in systolic, diastolic and mean arterial pressures were observed during the procedure in the non-vegetarian group, it was not significant when compared to the vegetarian group. Though statistically insignificant, it took a shorter time for all the parameters to return to normal levels 5 minutes after the procedure in the vegetarian group. In a study by Margetts et al. 
in people who consumed meat, a fall in systolic blood pressure by $5 \mathrm{mmHg}$ was seen when they stuck with a vegetarian diet which considerably rose on resuming a meat diet. ${ }^{17}$ Webster et al. found low systolic blood pressure and diastolic blood pressure in early adulthood when meat, alcohol, tobacco, caffeine were omitted from the diet. They also found a less rise in blood pressure with increasing age. 18

Studies have shown that plant protein lowers blood cholesterol levels. ${ }^{18,19}$ Hence, a low-fat, vegetarian diet has a clear advantage over other diets.

In untreated subjects with mild hypertension, changing to a vegetarian diet may bring about a worthwhile fall in systolic blood pressure. Whelton et al. concluded that a reduction of systolic blood pressure by just $5 \mathrm{mmHg}$ a $7 \%, 9 \%$ and $14 \%$ reduction in mortality due to all causes, coronary heart disease and stroke can be expected.20

\section{CONCLUSION}

The present study suggests that healthy children of hypertensive parents do have a sympathetic dominance when compared to healthy children of non-hypertensive parents. The exaggerated sympathetic response seen in stress may be used as a marker to detect people who may develop hypertension in future. Early lifestyle modifications like incorporating regular physical activity in the form of moderate exercises, making suitable changes in diet like reducing consumption of high caloric foods and including diets high in fruits, vegetables, low-fat dairy products, whole grains, nuts and unsaturated vegetable oils may be helpful in preventing development of hypertension. A prospective study in the same group after incorporating lifestyle and dietary modifications is needed to confirm the findings, as it may prove beneficial in reducing the global burden of hypertension on health care system.

\section{REFERENCES}

1. Raghupathy Anchala, Nanda K Kannuri, Hira Pant, et al. Hypertension in India: a systematic review and metaanalysis of prevelance, awareness and control of hypertension. Journal of Hypertension 2014,32:1170-77.

2. Gupta R, Gupta VP. Hypertension epidemiology in India: lessons from Jaipur heart watch. Current Science 2009;97:3.

3. Das SK, Sanyal K, Basu A. A study of urban community survey in India: growing trend of high prevelance of hypertension in a developing country. Int J Med Sci 2005;2:70-8.

4. Stolraz K, Grodzicki T, Lubaszawski W, et al. Heart rate variability in offsprings of hypertensive parents. Przegl Lek 2002;59:892-94.

5. Kasper, Fauci, Hauser, et al. In: Theodore A Kotchen eds. Hypertensive vascular disease: Harrisons principles of internal medicine. New York. Mc Graw Hill education. 2012;1611-26.
6. Olson RP, Kroon JS. Behavioural treatment of essential hypertension. Biofeedback: A Practioner's guide edited by Schwartz MS (The Guilford Press: New York) 316-339.

7. Schneider GM, Jacobs DW, Gevirtz RN, et al. Cardiovascular hemodynamic response to repeated mental stress in normotensive subjects at genetic risk of hypertension. J human Hypertension 2003;17:829-40.

8. Wilson MW, Sung BH, Pincomb GA, et al. Exaggerated pressor response to exercise in man at risk of hypertension. Am J Cardiol 1990;66:731.

9. Biagini M, Brassetti B, Pierangeli L, et al. Blood pressure response to exercise in young subjects with and without parental history of hypertension. J Hum Hypertens 1996;10(3):81-3.

10. Gerin W, Pickering GT. Association between delayed recovery of blood pressure after acute mental stress and parental history of hypertension. J Hypertens 1995;13:603-10.

11. Mathias CJ, Bannister R. Investigation of autonomic disorders. In: Bannister R, Mathias C, eds. Autonomic failure: a textbook of clinical disorders of the autonomic nervous system. Oxford university press. Oxford. 1992;266.

12. Dos Santos Antonio AM, Cardoso MA, do Amaral JAT, et al. Cardiac autonomic modulation adjustment in isometric exercises. Medical express 2015;2(1).

13. Friedman DB, Peel C, Mitchell JH. Cardiovascular responses to voluntary and non voluntary static exercise in humans. J Appl Physiol 1992;73(5):1982-5.

14. Lopes HF, Cansolin FM. Increased sympathetic activity in normotensive offspring of malignant hypertensive parents compared to offspring of normotensive parents. Braz J Med Biol Res 2008;41:849-53.

15. Sherwood A, Allen MP, Obrist PA, et al. Evaluation of beta-adrenergic influences on cardiovascular and metabolic influences on cardiovascular and metabolic adjustments to physical and physiological stress. Psychophysiology 1986;23:89-104.

16. De Lima JJ, Dias MM, Bernardes-Silva H, et al. Pressor response to nor-epinephrine in essential hypertension. A study in families. Hypertension 1990;15(2):137-39.

17. Margetts BM, Beilin LJ, Vandongen R, et al. Vegetarian diet in mild hypertension:a randomized controlled trial. Br Med J 1986;293(6560):1468-71.

18. Webster IW, Rawson GK. Health status of seventh-day adventists. Med J Aust 1979;1:417-20.

19. Beilin LJ, Margetts BM. Vegetarian diet and blood pressure. Bibl Cardiol 1987;41:85-105.

20. Whelton PK, HE J, Appel LJ, et al. National high blood pressure education program coordinating committee. Primary prevention of hypertension: clinical and public health advisory from the national high blood pressure education program. JAMA 2002;288(15):1882-88. 